Dominique Ehrmantraut, Livre des délibérations de l'Église française réformée de Frankenthal dans le Palatinat (1658-1689). Livre des délibérations de l'Église française réformée d'Otterberg dans le Palatinat (1659-1689).

Paris, Honoré Champion, coll. « Vie des Huguenots », 2011, 448 p.

Daniel-Odon Hurel

\title{
OpenEdition
}

Journals

Édition électronique

URL : http://journals.openedition.org/assr/24527

DOI : $10.4000 /$ assr. 24527

ISSN : $1777-5825$

Éditeur

Éditions de l'EHESS

Édition imprimée

Date de publication : 30 décembre 2012

Pagination : 164

ISSN : 0335-5985

Référence électronique

Daniel-Odon Hurel, « Dominique Ehrmantraut, Livre des délibérations de l'Église française réformée de Frankenthal dans le Palatinat (1658-1689). Livre des délibérations de l'Église française réformée d'Otterberg dans le Palatinat (1659-1689). », Archives de sciences sociales des religions [En ligne], 160 | octobre-décembre 2012, mis en ligne le 01 mars 2013, consulté le 21 septembre 2020. URL : http:// journals.openedition.org/assr/24527 ; DOI : https://doi.org/10.4000/assr.24527

Ce document a été généré automatiquement le 21 septembre 2020.

(c) Archives de sciences sociales des religions 


\section{Dominique Ehrmantraut, Livre des délibérations de l'Église française réformée de Frankenthal dans le Palatinat (1658-1689). Livre des délibérations de l'Église française réformée d'Otterberg dans le Palatinat (1659-1689).}

Paris, Honoré Champion, coll. « Vie des Huguenots », 2011, 448 p.

Daniel-Odon Hurel

\section{RÉFÉRENCE}

Dominique Ehrmantraut, Livre des délibérations de l'Église française réformée de Frankenthal dans le Palatinat (1658-1689). Livre des délibérations de l'Église française réformée d'Otterberg dans le Palatinat (1659-1689), Paris, Honoré Champion, coll. «Vie des Huguenots », 2011, 448 p. 
Quelle que soit l'institution, une paroisse catholique, un monastère ou une Église réformée, les registres de délibérations qui y sont liés constituent des sources essentielles et précieuses pour l'historien. Ce volume proposé par Dominique Ehrmantraut en est une nouvelle preuve. En éditant deux livres de délibérations de deux Églises françaises réformées du Palatinat à la même période, soit dans la seconde moitié du $\mathrm{XVII}^{\mathrm{e}}$ siècle, l'auteur nous livre à la fois une source riche et des introductions et annexes apportant une nouvelle pierre à l'édifice de la connaissance du Refuge huguenot dont les membres sont souvent dans un premier temps accueillis dans des couvents sécularisés. Ces deux textes, et plus spécifiquement celui de Frankenthal, évoquent bien entendu l'ensemble de la vie de la paroisse : règlements intérieurs, organisation, délibérations sur les dépenses, la discipline, les mariages, nominations des pasteurs et autres diacres et anciens. Ils montrent la place importante des questions de discipline et de mœurs et des réconciliations mais aussi la place centrale de l'éducation, de l'instruction et du catéchisme. Quelques abjurations sont mentionnées dont une particulièrement intéressante, car il s'agit de celle d'un bénédictin de Saint-Vincent de Metz, dom Arnauld Mamiel, dont nous avons ainsi connaissance de la confession de foi (p.163-167), document essentiel. Originaire de Metz, l'on peut ajouter qu'il s'agit sans doute du moine que la matricule de la Congrégation bénédictine de Saint-Vanne, prénomme Romuald et qui a fait profession, le 9 juin 1657 dans l'abbaye Saint-Vincent de Metz. S'il s'agit bien de lui, il est déclaré apostat en 1681 alors que sa décision date de 1664. Nous sommes donc en présence d'une abjuration bénédictine, fait que l'on connaît peu, au sein d'une congrégation connue pour son engagement dans l'exégèse et la théologie, en frontière de catholicité, réforme bénédictine illustrée bien entendu par dom Augustin Calmet quelques années plus tard. Le texte retranscrit dans le livre des délibérations de Frankenthal exprime très clairement les réflexions théologiques et dévotionnelles qui ont conduit à la décision prise par le religieux.

Une série d'annexes complète utilement ce volume, livrant des cartographies du Palatinat et des Églises réformées wallonnes-françaises, plusieurs prosopographies (diacres et anciens de Frankenthal, maîtres d'école et recteurs), différentes listes comme celle recueillant les noms des premiers paroissiens, les courbes des baptêmes et mariages de Frankenthal, les capitulations de Frankenthal et d'Otterberg (1562 et 1579), et différents sceaux. Ces différents documents constituent à la fois une mise en situation des documents, une première exploitation partielle, en particulier dans le domaine de l'étude des trajectoires personnelles de pasteurs, et des pistes pour les 
chercheurs parmi lesquelles l'histoire des réseaux réformés et des territoires de ces paroisses en est une importante. 